\title{
Superficial Cervical Artery
}

National Cancer Institute

\section{Source}

National Cancer Institute. Superficial Cervical Artery. NCI Thesaurus. Code C53005.

An artery arising from the thyrocervical trunk with branches that supply the trapezius

muscles as well as some muscles and glands in the neck. 